\title{
PENGAMATAN JENIS GULMA PADA TANAMAN POKOK JAGUNG (Zea mays L.)DI LAHAN SAWAH DESA BONGKASA ABIANSEMAL BADUNG, PROVINSI BALI.
}

\author{
OBSERVATION OF TYPES OF GULMA IN CORN (Zea mays L.) PLANT PLANTS \\ IN LAND SAWAH DESA BONGKASA ABIANSEMAL BADUNG, \\ BALI PROVINCE.
}

\author{
Komang Krisna, Martin Joni, I. B.Gd. Darmayasa \\ Biologi, FMIPA, Universitas Udayana, Bukit Jimbaran, Bali \\ Email : krisnaadikomang@gmail.com
}

\section{INTISARI}

Penelitian tentang inventarisasi gulma pada lahan jagung betujuan untuk meelihat keberagaman jenis gulma yang ada tumbuh pada lahan area tanaman jagung (Zea mays (L.)) di persawahan Desa Bongkasa Abiansemal Badung, Provinsi Bali. Pengamatan ini nantinya diharapkan untuk memperoleh informasi tentang jenis dari gulma yang ada, sehingga pengendalian dan pembrantasan gulma pada tanaman jagung (Zea mays (L.)) diimplementasikan secara optimal. Penelitian dilakukan dari bulan Juni-Agustus 2018. Dalam pengamatan menggunakan metode jelajah (exsplorating sampling). Agar hasil lebih baik dan sistematis, maka pengamatan dibuatkan lajur dan pengamatan pada lahan penelitian agar dapat dengan mudah mengamati tumbuhnya tanaman pengganggu yang tumbuh pada lahan tanaman jagung yang diamati. Di lahan tanaman jagung berumur 1 bulan ditemukan 8 suku dengan 16 jenis. Pada tanaman jagung berumur 2 bulan ditemukan 14 suku dengan 28 jenis gulma, sedangkan pada tanaman jagung yang berumur 3 bulan ditemukan sebanyak 22 suku dengan 40 jenis gulma. Adapun 22 suku tersebut adalah Amaranthaceae, Asteraceae, Balsaminaceae, Capparidaceae, Commelinaceae, Convolvulaceae, Cyperaceae, Euphorbiaceae, Goodeniaceae, Laminaceae, Mimosaceae, Loganiaceae, Malvaceae, Onagraceae, Oxalidaceae, Poaceae, Portulacaceae, Rubiaceae, Scrophulariaceae, Solanaceae, Urtcaceae, dan Violaceae, dengan 40 jenis yaitu Amaranthus gracilis (Desf), Amaranthus spinosus (L), Ageratum conoyzoides L., Eclipta alba L., Emilia sonchifolia (L.), Vernonia cinerea (L, Synedrella nodiflora (L.), Tridax procumbens, Impatatiens platypetalaL. Cleome rutidosperma DC., Cleome viscosaL, Murdania nudiflora (L.) Brenan, Impomea triloba L., Paedenia foetida L., Impomea gassicaulis Rot, Cyperus rotundus L. Kylliangia monocephala (Endl). Euphorbia hirta L. Phyllantus urinaria L., Phyllantus debilis Klein., Elephantopus scaber C., Basilicum polystachyon (L.), Mimosa pudica (L)., Spigelia anthelmia L., Sida rhombifolia L., Ludwigia perennis L., Oxalis corniculata L. Dactyloctenium aegyptium (L.), Digitaria ciliaris (Retz.), Eragrotis tenella (L.), Echinoclhoa colonum (L.), Elusine indica L., Portulaca oleraceae L., Hedyotis diffusa (L.) Lamk, Lindernia crustacea (L.), Scoparia dulcis L., Physalis angulata L., Capsicum frutescens, Urtica grandidentata $\mathrm{L}$, Hybanthus attenuates $\mathrm{L}$.

Kata kunci: gulma, Zea mays L., Desa Bongkasa.

\section{ABSTRCT}

Research on weed inventory in maize land aims to see the diversity of existing weeds growing on the area of corn (Zea mays (L.)) in the fields of Bongkasa Abiansemal Badung Village, Bali Province. This observation will be expected to obtain information about the types of weeds that exist, so that weeds and control of weeds in corn (Zea mays (L.)) are optimally implemented. The study was conducted from June to August 2018. In observations using an exsplorating sampling method. In order to produce better and more systematic results, observations were made to make lanes and observations on the research land so that it could easily observe the growth of disturbing plants growing on the observed maize crops. In a 1-month old corn plant, 8 tribes were found with 16 species. In the 2 month old corn plant, 14 tribes were found with 28 species of weeds, while in the 3 -month-old maize there were 22 tribes with 40 species of weeds. The 22 tribes are Amaranthaceae, Asteraceae, Balsaminaceae, Capparidaceae, Commelinaceae, Convolvulaceae, Cyperaceae, Euphorbiaceae, Goodeniaceae, Laminaceae, Mimosaceae, Loganiaceae, Malvaceae, Onagraceae, Oxalidaceae, Poaceae, Portulacaceae, Rubiaceae, Scrophulariaceae, Solanaceae, Urtcaceae, Violaceae, Urtcaceae, with 40 species namely Amaranthus gracilis (Desf), Amaranthus spinosus (L), Ageratum conoyzoides L., Eclipta alba L., Emilia sonchifolia (L.), Vernonia cinerea (L, Synedrella nodiflora (L.), Tridax procumbens, Impatatiens platypetalaL Cleome rutidosperma DC, Cleome viscosaL, Murdania nudiflora (L.) Brenan, Impomea triloba L., Paedenia foetida L., Impomea gassicaulis Rot, Cyperus rotundus L. Kylliangia monocephala (Endl). Euphorbia hirta L. Phyllantus urinaria L., Phyllantus debilis Klein. Elephantopus scaber C., Basilicum polystachyon (L.), Mimosa pudica (L). Spigelia anthelmia L., Sida rhombifolia L., Ludwigia perennis L., Oxalis corniculata L. Dactyloctenium aegy ptium (L.), Digitaria ciliaris (Retz.), Eragrotis tenella (L.), Echinoclhoa colonum (L.), Elusine indica L., Portulaca oleraceae L., Hedyotis diffu sa (L.) Lamk, Lindernia crustacea (L.), Scoparia dulcis L., Physalis angulata L., Capsicum frutescens, Urtica grandidentata L, Hybanthus attenuates L.

Keywords: weed, Zea mays L., Bongkasa Village.

\section{PENDAHULUAN}

Tanaman jagung merupakan komoditas pangan utama penghasil sumber karbohidrat kedua setelah beras di Indonesia. Jagung juga mengandung protein, zat kalsium, fosfor, lemak, besi, hidrat arang, vitamin C, A, dan B1. (Rukmana 2003). Tanaman jagung pertamakali dibudidayakan di pegunungan Andes, Amerika selatan 4.500 tahun yang lalu, sampai di Indonesia dibawa oleh pedagang dari Portugis sekitar 400 tahun yang lalu (Rukmana dan Yudirachman, 2007). Pulau Jawa menjadi sentra produksi jagung di Indonesia yang menghasilkan produksi jagung hingga $65 \%$, dan luar pulau Jawa sebanyak 35\%
(Rukman 2003). Pembudidayaan jagung tidak memiliki persyaratan lahan tanah yang khusus dalam penanaman, karena jagung dapat tumbuh pada lahan yang kering, persawahan, dan daerah pantai. Produksi hasil panen terpengaruhi oleh beberpa faktor diantaranya tanah atau tempat tumbuh, ketersediaan air, dan iklim lingkungan di areal lahan budidaya. Supaya produksi jagung menghasilkan biji yang banyak dan baik maka harus sesuai dengan syarat tumbuh tanaman jagung yaitu sesuai dengan tempat tumbuh, ketersediaan air, dan iklim syrat tumbuh tanaman jagung. (Purwono dan Hartono). Jagung mempunyai sistem perakaran serabut, batang beruas, tiap ruas terpisah oleh 
buku-buku batang tidak bercabang, dan daun jagung keluar dari buku-buku batang, jagung termasuk bunga taklengkap, bunga jagung juga termsuk bunga taksempurna dikarenakan bunga jantan dan betina tidak dalam satu bunga namun dalam satu pohon. (Purwono dan Hartono).

Tanaman pengganggu yang juga disebut dengan gulma adalah suatu tanaman yang tumbuh pada tanaman budidaya, tanaman yang tumbuh disekitar tanaman yang sengaja dibudidayakan, gulma juga disebut tanaman yang mengakibatkan kerugian pada tanaman budidaya karena kehadirannya merugikan tanaman pokok, kehadiran gulma pada tanaman pokok dapat merugikan dan menurunkan hasil produksi hingga 50\% (Moenandir, 1990). Kompetisi antara tanaman pokok dengan gulma dalam pemanpaatan keperluan dasar yang sama yakni penyerapan unsur-ensur hara, air, cahaya, rung tempat tumbuh dan $\mathrm{CO}_{2}$ akan terjadi. (Sukma dan Yakup, 1999). Keberadaan gulma sangat berpengaruh merugikan bagi tanaman budidaya jagung, dan gulma dapat menurunkan hasil produksi, gulma juga mengakibatkan matinya tanaman pokok karena gulma mengeluarkan senyawa kimia saat berkompetisi untuk tumbuh dengan tanaman budidaya. (Sembodo, 2010). Dengan demikian penulis dalam kesepatan ini sangat berkeinginan untuk meneliti dan menginventarisasi jenis-jenis gulma yang ada bersama dengan tanaman pokok jagung di lahan persawahan di Desa Bongkasa Abiansemal Badung, Provinsi Bali, nantinya jenis-jenis gulma yang ada telah diketahui maka dalm pengendalian dan pembratasan gulma dapat dilakukan dengan baik.

\section{MATERI DAN METODE}

Metode pengambilan data meliputi tempat dan waktu, inventarisasi serta identifikasi keberagaman jenis gulma yang ada tumbuh pada lahan penelitian tanaman budidaya di lahan persawahan desa Bongkasa Abiansemal Badung, Provinsi Bali. Penelitian akan dilakukan dari bulan Juni- Agustus 2018. Pada saat penelitianmetode yang dipakai adalah metode pengamatan langsung dengan menjelajahi areal tanaman jagung (exploration sampling). Merupakan metode pengamatan langsung ke lapangan dengan cara mencatat jenis-jenis gulma yang tumbuh di Lapangan. Gulma yang sudah teridentifikasi namanya langsung dicatat, sedangkan gulma yang belum diketahui diambil untuk diidentifikasi. Untuk pengamatan agar lebih efisien dan sistematis di lahan sawah yang luasnya sekitar 150 Ha yang ditanami tanaman jagung pada saat penelitian, maka digunakan bantuan garis atau rintisan diantara gundukan secara lurus memanjang mengikuti arah gundukan agar tidak mengganggu tanaman jagung pada saat diamati (Sembodo, 2010). Jenis gulma yang diamati langsung dengan menentukan nama spesies dengan menggunakan acuan buku identifikasi yang berjudul Keberagaaman jenis gulma di Indonesia (Soerjani et al., 1987), Atlas of 220 Jenis-jenis gulma pada tanaman tebu di daerah jawa (Backer,1973), dan The World's Worst Weeds (Holm et al.,1988)

\section{HASIL PENGAMATAN}

Pengamatan gulma pada lahan tanaman jagung diperoleh hasil secara keseluruhan sebanyak 40 jenis, dari 22 suku. Adapunjenis-jenis gulma yang ada tumbuh di lahan persawahan, Desa Bongkasa, Abiansemal, Badung, Provinsi Bali. Terlampir dalam tabel 1.

Tabel 1. Jenis-jenis gulma yang ditemukan tumbuh di area tanaman jagung (Zea mays.L.) yangberumur 1 bulan dalam tabel 1

\begin{tabular}{|c|c|c|c|}
\hline No & Suku & Jenis & Nama Daerah/ Indonesia \\
\hline 1 & Amaranthaceae & $\begin{array}{l}\text { Amaranthus spinosus L. } \\
\text { Amaranthus gracilis (Desf) }\end{array}$ & $\begin{array}{l}\text { Bayem berduri } \\
\text { Bayem }\end{array}$ \\
\hline 2 & Asteraceae & $\begin{array}{l}\text { Ageratum conoyzoides } \mathrm{L} . \\
\text { Eclipta alba } \mathrm{L} . \\
\text { Emilia sonchifolia }(\mathrm{L} .) \\
\text { Vernonia cinerea }(\mathrm{L}) \mathrm{Less} \\
\text { Synedrella nodiflora }(\mathrm{L} .) \text { Gaertn } \\
\text { Tridax procumbens } \mathrm{L} .\end{array}$ & $\begin{array}{l}\text { Bandotan / buyung-buyung } \\
\text { Orang aring } \\
\text { Patah kemudi } \\
\text { Buyung -buyung } \\
\text { Jukut barak kambing } \\
\text { Gletang }\end{array}$ \\
\hline 3 & Commelinaceae & Murdania nudiflora (L.) & sangkar burung \\
\hline 4 & Cyperaceae & $\begin{array}{l}\text { Cyperus rotundus L. } \\
\text { Kylliangia monocephala L. }\end{array}$ & $\begin{array}{l}\text { Jekeng } \\
\text { Wudelan, Teki badot }\end{array}$ \\
\hline 5 & Euphorbiaceae & $\begin{array}{l}\text { Euphorbia hirta } \\
\text { Phyllantus urinaria L. }\end{array}$ & $\begin{array}{l}\text { Jagut-jagut } \\
\text { Meniran }\end{array}$ \\
\hline 6 & Mimosaceae & Mimosa pudica $\mathrm{L}$. & Keket \\
\hline 7 & Oxalidaceae & Oxalis corniculata $\mathrm{L}$. & Piduh. \\
\hline 8 & Portulacaceae & Portulaca oleraceae L. & Krekot/ Krokot \\
\hline Jumlah & $8 \mathrm{Suku}$ & 16 Jenis & \\
\hline
\end{tabular}

Tabel 2. Jenis-jenis gulma yang ditemukan tumbuh di area tanaman jagung (Zea mays.L.) yangberumur 2 bulan didapatkan 14 Suku dan 28 Jenis dalam tabel 2. 


\begin{tabular}{|c|c|c|c|}
\hline No & Suku & Jenis & $\begin{array}{l}\text { Nama Daerah/ } \\
\text { Indonesia }\end{array}$ \\
\hline 1 & Amaranthaceae & $\begin{array}{l}\text { Amaranthus spinosus (L.) } \\
\text { Amaranthus gracilis (Desf) }\end{array}$ & $\begin{array}{l}\text { Bayem medui/ Bayam } \\
\text { berduri } \\
\text { Bayem/ Bayam }\end{array}$ \\
\hline 2 & Asteraceae & $\begin{array}{l}\text { Ageratum conoyzoides L. } \\
\text { Eclipta alba } \mathrm{L} . \\
\text { Emilia sonchifolia (L.) } \\
\text { Vernonia cinereaLess } \\
\text { Synedrella nodiflora (L.) } \\
\text { Tridax procumbens (L). }\end{array}$ & $\begin{array}{l}\text { Bandotan } \\
\text { Orang aring } \\
\text { Patah kemudi } \\
\text { Buyung -buyung } \\
\text { Jukut barak kambing } \\
\text { Gletang }\end{array}$ \\
\hline 3 & Cappridaceae & $\begin{array}{l}\text { Cleome rutidosperma Dc } \\
\text { Cleome viscosa } \mathrm{L} \text {. }\end{array}$ & $\begin{array}{l}\text { kembang ungu } \\
\text { kembang kuningan }\end{array}$ \\
\hline & Commelinaceae & Murdania nudiflora (L.) & sangkar burung \\
\hline 5 & Cyperaceae & $\begin{array}{l}\text { Cyperus rotundus } \mathrm{L} . \\
\text { Kylliangia monocephala (Endl). }\end{array}$ & $\begin{array}{l}\text { Jekeng } \\
\text { Wudelan, Teki badot }\end{array}$ \\
\hline 6 & Euphorbiaceae & $\begin{array}{l}\text { Euphorbia hirta } \mathrm{L} . \\
\text { Phyllantus urinaria } \mathrm{L} .\end{array}$ & $\begin{array}{l}\text { Jagut-jagut } \\
\text { Meniran }\end{array}$ \\
\hline 7 & Mimosacaeae & Mimosa pudica L. & Putri malu. Keket \\
\hline 8 & Oxalidaceae & Oxalis corniculata & Semanggi.Piduh. \\
\hline 9 & Poaceae & $\begin{array}{l}\text { Dactyloctenium aegyptium (L.) } \\
\text { Digitaria ciliaris }(\text { Retz.). } \\
\text { Eragrotis tenella }(\mathrm{L} .) \\
\text { Echinochloa colonum }(\mathrm{L} .) \\
\text { Elusine indica }(\mathrm{L} .)\end{array}$ & $\begin{array}{l}\text { Suket } \\
\text { Rumput cakar ayam } \\
\text { Empritan. } \\
\text { Padang kili } \\
\text { Rumput kusa-kusa }\end{array}$ \\
\hline 10 & Portulacaceae & Portulaca oleraceae L. & Krekot/ Krokot \\
\hline 11 & Rubiaceae & Hedyotis diffusa (L.) Lamk & Katepan \\
\hline 12 & Scrophulariaceae & $\begin{array}{l}\text { Lindernia crustacea }(\mathrm{L} .) \\
\text { Scoparia dulcis }(\mathrm{L} .)\end{array}$ & $\begin{array}{l}\text { Daun sirih ketok } \\
\text { Jaka tua }\end{array}$ \\
\hline 13 & Solanaceae & Physalis angulate $\mathrm{L}$. & Ciplukan \\
\hline 14 & Violaceae & $\begin{array}{l}\text { Hybanthus attenuatus (Humb. \& } \\
\text { Bond.) G.K Schulze }\end{array}$ & Kembang bintang \\
\hline Jumlah & 14 Suku & 28 Jenis & \\
\hline
\end{tabular}

Tabel 3. Jenis-jenis gulma yang ditemukan tumbuh di area tanaman jagung (Zea mays.L.) yangberumur 3 bulan didapatkan 22 Suku 40 Jenis dapat dilihat dalam tabel 3

\begin{tabular}{|c|c|c|c|}
\hline No & Suku & Jenis & Nama Daerah/ Indonesia \\
\hline 1. & Amaranthaceae & $\begin{array}{l}\text { Amaranthus gracilis }(\mathrm{Desf}) \\
\text { Amaranthus spinosus }(\mathrm{L})\end{array}$ & $\begin{array}{l}\text { Bayam } \\
\text { Bayam berduri / bayem madui }\end{array}$ \\
\hline 2. & Asteraceae & $\begin{array}{l}\text { Ageratum conoyzoides } \mathrm{L} . \\
\text { Eclipta alba } \mathrm{L} . \\
\text { Emilia sonchifolia }(\mathrm{L} .) \\
\text { Vernonia cinereaLess } \\
\text { Synedrella nodiflora }(\mathrm{L} .) \\
\text { Tridax procumbens }(\mathrm{L} .)\end{array}$ & $\begin{array}{l}\text { Bandotan / buyung-buyung } \\
\text { Orang aring } \\
\text { Patah kemudi } \\
\text { Buyung -buyung } \\
\text { Jukut barak kambing } \\
\text { Gletang }\end{array}$ \\
\hline 3 & Balsaminaceae & Impatiens platypetala $\mathrm{L}$. & Pacar air \\
\hline 4 & Capparidaceae & $\begin{array}{l}\text { Cleome rutidosperma DC. } \\
\text { Cleome viscosa } \mathrm{L} .\end{array}$ & $\begin{array}{l}\text { Kembang ungu } \\
\text { Kembang kuningan }\end{array}$ \\
\hline 5 & Commelinaceae & Murdania nudiflora (L.) & Sangkar burung \\
\hline 6 & Convolvulaceae & $\begin{array}{l}\text { Impomea triloba } \mathrm{L} . \\
\text { Paedenia foetida } \mathrm{L} . \\
\text { Impomea gassicaulis Rot }\end{array}$ & $\begin{array}{l}\text { Daun kentut, kesimbukan(Bali) } \\
\text { Kangkung }\end{array}$ \\
\hline 7 & Cyperaceae & $\begin{array}{l}\text { Cyperus rotundus } \mathrm{L} . \\
\text { Kylliangia monocephala (Endl). }\end{array}$ & $\begin{array}{l}\text { Jekeng } \\
\text { Wudelan, Teki badot }\end{array}$ \\
\hline 8 & Euphorbiaceae & $\begin{array}{l}\text { Euphorbia hirta L. } \\
\text { Phyllantus urinaria L. } \\
\text { Phyllantus debilis Klein ex Wild. }\end{array}$ & $\begin{array}{l}\text { Jagut-jagut } \\
\text { Meniran } \\
\text { Meniran }\end{array}$ \\
\hline 9 & Goodeniaceae & Elephantopus scaber C. & Tapak liman \\
\hline 10 & Lamiaceae & Basilicum polystachyon (L.) Moench & Sangket \\
\hline 11 & Mimosaceae & Mimosa pudica $\mathrm{L}$. & Putri malu. Keket \\
\hline 12 & Loganiaceae & Spigelia anthelmia L. & Jukut punter \\
\hline 13 & Malvaceae & Sida rhombifolia $\mathrm{L}$. & Sidaguri \\
\hline 14 & Onagraceae & Ludwigia perennis L. & Cabe-cabean \\
\hline 15 & Oxalisdaceae & Oxalis corniculata $\mathrm{L}$. & Semanggi gunung.Piduh. \\
\hline 16 & Poaceae & $\begin{array}{l}\text { Dactyloctenium aegyptium L. } \\
\text { Digitaria ciliaris }(\mathrm{L} .) \\
\text { Eragrotis tenella }(\mathrm{L} .) \\
\text { Echinoclhoa colonum }(\mathrm{L} .) \\
\text { Elusine indica }(\mathrm{L}) .\end{array}$ & $\begin{array}{l}\text { Suket } \\
\text { Rumput cakar ayam } \\
\text { Empritan. } \\
\text { Padang kili } \\
\text { Rumput kusa-kusa/ Belulang }\end{array}$ \\
\hline 17 & Portulacaceae & Portulaca oleraceae L. & Krokot \\
\hline
\end{tabular}




\begin{tabular}{|c|l|l|l|}
\hline 18 & Rubiaceae & Hedyotis diffusa (L.) Lamk & Katepan \\
\hline 19 & Scrophulariaceae & $\begin{array}{l}\text { Lindernia } \text { crustacea } \text { (L.) } \\
\text { Scoparia dulcis(L.) }\end{array}$ & $\begin{array}{l}\text { Daun sirih ketok } \\
\text { Jaka tua }\end{array}$ \\
\hline 20 & Solanaceae & $\begin{array}{l}\text { Physalis angulata } \text { L. } \\
\text { Capsicum frutescens }\end{array}$ & $\begin{array}{l}\text { Ciplukan } \\
\text { Cabe Lombok }\end{array}$ \\
\hline 21 & Urticaceae & Urtica grandidentata Miq Non Moris & Daun gatal, Lateng \\
\hline 22 & Violaceae & $\begin{array}{l}\text { Hybanthus attenuatus (Humb. \& Bond.) } \\
\text { G.K Schulze }\end{array}$ & Kembang bintang \\
\hline Jumlah & 22 Suku & 40 Jenis & \\
\hline
\end{tabular}

\section{PEMBAHASAN}

Tanaman Jagung 3 bulan tahap menjelang panen di Desa Bongkasa, Abiansemal, Badung, Popinsi Bali secara keseluruhan ditemukan gulma sebanyak 22 Suku dari 40 Jenis. Peneliti memilih umur tanaman jagung pada umur masa tanam tersebut dikarenakan pada umur tanaman jagung paling banyak ditemukan jumlah tanaman pengganggu, disetiap perbandingan umur jagung yakni umur tanaman jagung 1 bulan ditemukan 16 jenis dari 8 suku gulma, pada umur tanaman jagung 2 bulan ditemukan 28 jenis dari 14 suku gulma, dan pada umur tanaman jagung 3 bulan ditemukan 40 jenis dari 22 suku gulma, adapun jenis gulma yang mendominasi disetiap perbedaan umur tanaman jagung, pada umur tanaman jagung 1 bulan didominasi oleh suku Asteraceae dan Cyperceae, sedangkan pada umur tanaman jagung umur 2 dan 3 bulan didominasi oleh suku Astercaea, Cyperaceae, dan Poaceae. Dari keseluruhan jenisjenis gulma yang ditemukan dari suku Amaranthaceae, Asteraceae, Balsaminaceae, Capparidaceae, Commelinaceae, Convolvulaceae, Laminaceae, solanaceae, Urticaceae, dan Violaceae merupakan suku-suku gulma yang termasuk dalam gulma berdaun lebar, jenis-jenis dari suku gulma tersebut ditemukan merata diseluruh area penelitian dikarenakan dari keseluruhan jenis tersebut meiliki biji yang banyak dan sistem perakaran yang kuat oleh karena itu suku tersebutditemukan merata di seluruh area penelitian, sesuai dengan pernyataan dari Sastroutomo dan Sutikno (1999) yang menyatakan gulma yang memiliki biji yang banyak mudah menyebar dan tumbuh secara merata di seluruh areal lahan penanaman budidaya jagung itu sendiri, sehingga tidak meratanya pertumbuhan jagung yang tidak merata maka lahan yang kosong akan ditempati oleh gulma, sesuai dengan yang dinyatakan oleh pendapat Rukmana dan Yudirachman (2007), menyatakan ruang yang kosong yang tidak ditumbuhi tanaman pokok berpeluang besar akan pasti ditumbuhi gulma. Dari semua jenis gulma ini memiliki kemampuan adaptasi yang tinggi dengan lingkungannya mampu bertahan dengan ketersediaan air yang rendah dan tahan terhadap naungan, Rader dan Buck (2000).

Suku gulma yang termasuk dalam karakter gulma berdaun sempit yakni, suku Cyperceae, Euphorbiaceae, Mimosaceae, Loganiaceae, Malvaceae, Onagraceae, Oxsalidaceae, Poaceae, Portulacaceae, Rubiaceae, dan Scrophulariaceae, jenis dari keseluruhan suku ini memiliki kemampuan beradaptasi tinggi yang sesuai dengan pendapat Holm et al, menyatak gulma jenis ini termasuk gulma yang kuat berkemampuan adaptasi tinggi, berkembang melalaui biji, perakaran yang kuat, memiliki umbi termasuk dalam karakter gulma ganas. Persainag gulma dengan tanaman budidaya dalam pemanpaatan penyerapan unsur hara, air, cahaya pasti terjadi tentunya hal tersebut merugikan tanaman budidaya dalam pemanfaatannya sesuai dengan pernyataan dari Sukman dan Yakup, (1999) berpedapat bahwa antara gulma dan tanaman budidya bersaing atau berkompetisi dalam keperluan untuk tumbuh dan berkembang dalam memanfaatkan menyerap unsur hara, air, cahaya, rung tempat tumbuh, dan $\mathrm{CO}_{2}$.

\section{KESIMPULAN}

Kesimpulan yang dapat ditarik dari penelitian inventarisasi gulma pada lahan sawah di Desa Bongkasa Kecamatan Abinsemal Badung, Provinsi Bali. tanaman jagung berumur 1 bulan ditemukan 8 suku dengan 16 jenis gulma, tanaman jagung berumur 2 bulan ditemukan 14 suku dengan 28 jenis gulma, sedangkan tanaman jagung yang berumur 3 bulan ditemukan sebanyak 22 suku dengan 40 jenis gulma Pada tanaman jagung umur 1 bulan didominasi oleh familia Asteraceae dan Cyperaceae, pada tanaman jagung umur 2 bulan dan 3 bulan didominasi oleh familia Asteracea, Cyperaceae, dan Poaceae, dengan demikian telah diketahui jenis-jenis gulma yang ada tumbuh dilahan area tanaman budidaya dimana diharapkan setelah diketahui pembrantasan dan pengendalian gulma dapat dilaksanakan dengan optimal

\section{KEPUSTAKAAN}

Becker. 1973. Atlas of 220 Weeds of Sugar-cane Field in Java. Jakarta

Holm, Ronald L. Pluckneet, Juan V. Pancho, James P. Herberger. 1988. The World's Worst Weeds. University Press of Hawai.

Moenandir, J. 2010. Persaingan Tanaman Budidaya Dengan Gulma.Penerbit CV. Rajawali.Jakarta.

Purwono dan Hartono, R. 2008. Bertanam Jagung Unggul. Penebar Swadaya. Jakarta.

Reder dan Buck. 2000. Pertumbuhan Gulma Pada Kondisi Lingkungan. PT. Gramedia Press. Jakarta

Rukmana, R. 2003. Produksi Jagung di Indonesia. Penerbit aneka Ilmu. Semarang.

Rukmana, R dan Yudirachman, H. 2007. Jagung Budi Daya, Pasca Panen, dan Penganekaragaman Pangan Penerbit Aneka Ilmu. Semarang.

Sastroutomo dan Sutikno, S. 1999. Ekologi Gulma. PT. Gramedia Pustaka Utama. Jakarta

Sembodo, D.R.J. 2010. Gulma dan Pengolahannya. Penerbit Graha Ilmu. Edisi Pertama. Yogyakarta.

Soerjani, M. Koestermans, A.J.G.H and G. Tjitrosoepomo, 1987. Weed of Rice in Indonesia. Balai Pustaka. Jakarta

Sukman dan Yakup. 1999. Gulma dan Teknik Pengendaliannya. Fakultas pertanian Universitas Sriwijaya. Palembang.

Tjitrosoedirjo, S. IS Hidayat, U. Joedojono, W. 2010. Pengolahan Gulma di Lahan Perkebunan. PT. Gramedia. Jakarta. 
SIMBIOSIS VII (1): $1-5$

Jurusan Biologi FMIPA Universitas Udayana

$\cap \triangle 1$ DIRECTORY OF
ISSN: 2656-7784

http://ojs.unud.ac.id/index.php/simbiosis 